\title{
Often times, we should look at IVF more simply
}

\author{
Bruno Ramalho de Carvalho
}

GENESIS - Center for Assistance in Human Reproduction, Brasília, Distrito Federal, Brazil.

In our daily routine we find it difficult to deal with certain facts, to accept reality when it differs from what we desire. And in our practice as reproductive medicine specialists, it is not different. Every time an infertile couple enters our offices, we already know that chances of reproductive success are smaller than we would like them to be, even in the context of in vitro fertilization (IVF). Moreover, given the importance of the issue and its emotional burden, those chances of success become discouragingly small.

As we try to help couples to overcome the challenge of becoming parents, knowledge in reproductive medicine is continuously growing, and the advancements made in virtually every of its areas have been well recognized by the scientific community. Such developments have helped us to better understand and change the processes that negatively affect one's reproductive potential. However, in the words of Shakespeare (The Tragedy of Hamlet, Prince of Denmark), there are more things in heaven and earth than are dreamt of in [our] philosophy, and the volume of research and findings is not directly proportional to the volume of practical benefits they bring. Ultimately, therapeutic results have not changed significantly in recent years.

Among the processes involved in human procreation, biological events determine success (Diedrich et al., 2007) as much as or more than any single external intervention or set of interventions. In other words, the best embryo transferred to the best endometrium may not result in pregnancy or live birth if the apposition is not adequate for implantation. The success of this very first event of connection between the embryo and the mother-to-be is absolutely multifactorial; in practice, our interventions may just contribute until the moment of embryo transfer, while the next steps are the subject of chance and nature. So, in reproductive medicine, some could say that the size of the unknown is at least very close to the size of efficacy.

Regarding interventions for better reproductive results, good quality data published in worldwide renowned journals differ on simple strategies such as the pre-treatment use of contraceptives. In this particular topic, literature recently witnessed an elegant scientific debate (Garcia-Velasco \& Fatemi, 2015; Orvieto, 2015; Griesinger et al., 2015), in which strong arguments moving between extreme truths were not able to lead knowledge off a half-shade scenario. Even patient resting after embryo transfer, which is a common practice considered as evidently beneficial, has been treated with a sizable share of doubt in recent studies (Gaikwad et al., 2013; Abou-Setta et al., 2014).

Cutting-edge technologies have been generally insufficient to provide consensual solutions, as we seem to be yet far from seeing the light at the end of the tunnel. Strategies such as sperm selection under ultra-high magnification (Teixeira et al., 2013; McDowell et al., 2014), immunotherapy (Seshadri \& Sunkara, 2014; Polanski et al., 2014a), endometrial receptivity array (Blesa et al., 2014; von Grothusen et al., 2014), endometrial injury (El-Toukhy et al., 2012; Potdar et al., 2012; Nastri et al., 2015), timelapse imaging (Polanski et al., 2014b; Armstrong et al., 2015; Racowsky et al., 2015), assisted hatching (Martins et al., 2011; Carney et al., 2012) and preimplantation genetic screening (Gleicher et al., 2014; Lee et al., 2015; Dahdouh et al., 2015) have been the subject of contro- versy in recent reviews, with the quality of the evidence supporting their use still ranging between weak and poor. As a matter of fact, despite the volumes of research produced, we still do not know what really sets a right strategy apart from a wrong one. As usual, further good quality studies are necessary to furnish sufficient evidence before recommending any of the aforementioned interventions in clinical practice.

Previous studies on emotional burden have elicited complaints of anxiety, depression and stress among women offered in vitro fertilization (Verhaak et al., 2007; Verhaak et al., 2010), but although common sense indicates these symptoms are sustained after unsuccessful treatment cycles, it is not clear whether the excess of interventions or investigative tests are actual risk factors for emotional overload. Meanwhile, some - members of medical staffs at infertility centers included - assume that too many complementary tests in clinical practice may lead to precocious conclusions and worthless interventions (Dentillo, 2012). Then, the question is: assuming the excess of interventions is a psychological burden aggravating factor, are we really helping infertile couples when we offer them unproven procedures? And more, for how many couples will these interventions only contribute to the construction of a stage in which the suffering of a childless post-treatment life is enacted? These are only some of the tough questions our practice entails.

Without a doubt, in infertility treatment unrelated to research, experimental procedures and unproductive laboratory tests should not be ordered, mainly when the costs significantly outweigh the benefits. I admit that this is a pragmatic view and recognize that some patients might benefit from non-conventional strategies in individualized approaches. However, it seems to me that we have been overprescribing controversial treatments and, although the intention is to help rather than harm the patients, we should see IVF processes and outcomes in a more humanized way.

In reproductive medicine, the evolution of knowledge often brings more challenges than answers; a goal, when achieved, does not necessarily translate into an expected outcome, but into multiple new targets or even a few steps back. We must train ourselves to think outside the box, and realize what patients really need when they get into our offices. Now, it seems that innovation is looking back at simplicity and investments may lead to improvements to make IVF less troublesome, with measures such as the development of patient-friendly, cost-effective, good quality ovarian stimulation protocols (Patil, 2014).

Having a baby is the "what", but I am definitely sure that the "how" progressively gets more and more important. A positive treatment experience from the diagnosis of infertility to the finish line must be considered as an alternative goal, even when the finish line is a negative result. Having a less stressful approach should be considered as important as the couple having a baby to take back home with them in the end. Technology is always welcome in the right and individually determined case, but we are now facing different challenges for efficiency, which bring us to a simpler and morally expected behavior. Maybe, by being less invasive and more confident in the imperfect perfec- 
tion of nature during the whole process, it would help us to look at IVF more simply.

\section{REFERENCES}

Abou-Setta AM, Peters LR, D'Angelo A, Sallam HN, Hart RJ, Al-Inany HG. Post-embryo transfer interventions for assisted reproduction technology cycles. Cochrane Database Syst Rev. 2014;8:CD006567.

Armstrong S, Arroll N, Cree LM, Jordan V, Farquhar C. Time-lapse systems for embryo incubation and assessment in assisted reproduction. Cochrane Database Syst Rev. 2015;2:CD011320.

Blesa D, Ruiz-Alonso M, Simón C. Clinical management of endometrial receptivity. Semin Reprod Med. 2014;32:410-3.

Carney SK, Das S, Blake D, Farquhar C, Seif MM, Nelson L. Assisted hatching on assisted conception (in vitro fertilisation (IVF) and intracytoplasmic sperm injection (ICSI). Cochrane Database Syst Rev. 2012;12:CD001894.

Dahdouh EM, Balayla J, Audibert F; Genetics Committee, Wilson RD, Audibert F, Brock JA, Campagnolo C, Carroll J, Chong K, Gagnon A, Johnson JA, MacDonald W, Okun N, Pastuck M, Vallée-Pouliot K. Technical Update: Preimplantation Genetic Diagnosis and Screening. J Obstet Gynaecol Can. 2015;37:451-63.

Dentillo DB. Excesso de exames para detecção de doenças pode gerar diagnósticos prematuros e ações desnecessárias. Cienc Cult. 2012; 64(3):10-3.

Diedrich K, Fauser BC, Devroey P, Griesinger G; Evian Annual Reproduction (EVAR) Workshop Group. The role of the endometrium and embryo in human implantation. Hum Reprod Update. 2007;13:365-77.

El-Toukhy T, Sunkara S, Khalaf Y. Local endometrial injury and IVF outcome: a systematic review and meta-analysis. Reprod Biomed Online. 2012;25:345-54.

Gaikwad S, Garrido N, Cobo A, Pellicer A, Remohi J. Bed rest after embryo transfer negatively affects in vitro fertilization: a randomized controlled clinical trial. Fertil Steril. 2013; 100:729-35.

Garcia-Velasco JA, Fatemi HM. To pill or not to pill in GnRH antagonist cycles: that is the question! Reprod Biomed Online. 2015; 30:39-42.

Gleicher N, Kushnir VA, Barad DH. Preimplantation genetic screening (PGS) still in search of a clinical application: a systematic review. Reprod Biol Endocrinol. 2014;12:22.

Griesinger G, Venetis CA, Tarlatzis B, Kolibianakis EM. To pill or not to pill in GnRH-antagonist cycles: the answer is in the data already! Reprod Biomed Online. 2015; 31:6-8.

Lee $E$, Illingworth $P$, Wilton $L$, Chambers GM. The clinical effectiveness of preimplantation genetic diagnosis for aneuploidy in all 24 chromosomes (PGD-A): systematic review. Hum Reprod. 2015; 30:473-83. Martins WP, Rocha IA, Ferriani RA, Nastri CO. Assisted hatching of human embryos: a systematic review and me- ta-analysis of randomized controlled trials. Hum Reprod Update. 2011;17:438-53.

McDowell S, Kroon B, Ford E, Hook Y, Glujovsky D, Yazdani A. Advanced sperm selection techniques for assisted reproduction. Cochrane Database Syst Rev. 2014;10:CD010461.

Nastri CO, Gibreel A, Raine-Fenning N, Maheshwari A, Ferriani RA, Bhattacharya S, Martins WP. Endometrial injury in women undergoing assisted reproductive techniques. Cochrane Database Syst Rev. 2015;3:CD009517.

Orvieto R. To pill or not to pill in GnRH antagonist cycles: what should be the appropriate wash-out period? Reprod Biomed Online. 2015;30:557

Patil M. Gonadotrophins: The future. J Hum Reprod Sci. 2014;7:236-48.

Polanski LT, Barbosa MA, Martins WP, Baumgarten MN, Campbell B, Brosens J, Quenby S, Raine-Fenning N. Interventions to improve reproductive outcomes in women with elevated natural killer cells undergoing assisted reproduction techniques: a systematic review of literature. Hum Reprod. 2014a;29:65-75.

Polanski LT, Coelho Neto MA, Nastri CO, Navarro PA, Ferriani RA, Raine-Fenning N, Martins WP. Time-lapse embryo imaging for improving reproductive outcomes: systematic review and meta-analysis. Ultrasound Obstet Gynecol. 2014b;44:394-401.

PotdarN, GelbayaT, Nardo LG. Endometrial injury to overcome recurrent embryo implantation failure: a systematic review and meta-analysis. Reprod Biomed Online. 2012;25:561-71.

Racowsky C, Kovacs P, Martins WP. A critical appraisal of time-lapse imaging for embryo selection: where are we and where do we need to go? J Assist Reprod Genet. 2015; 32:1025-30.

Seshadri S, Sunkara SK. Natural killer cells in female infertility and recurrent miscarriage: a systematic review and meta-analysis. Hum Reprod Update. 2014;20:429-38.

Teixeira DM, Barbosa MA, Ferriani RA, Navarro PA, Raine-Fenning N, Nastri CO, Martins WP. Regular (ICSI) versus ultra-high magnification (IMSI) sperm selection for assisted reproduction. Cochrane Database Syst Rev. 2013; 7:CD010167.

Verhaak CM, Lintsen AM, Evers AW, Braat DD. Who is at risk of emotional problems and how do you know? Screening of women going for IVF treatment. Hum Reprod. $2010 ; 25: 1234-40$

Verhaak CM, Smeenk JM, Nahuis MJ, Kremer JA, Braat DD. Long-term psychological adjustment to IVF/ICSI treatment in women. Hum Reprod 2007;22:305-8.

von Grothusen C, Lalitkumar S, Boggavarapu NR, Gemzell-Danielsson K, Lalitkumar PG. Recent advances in understanding endometrial receptivity: molecular basis and clinical applications. Am J Reprod Immunol. 2014;72:14857. 